\title{
Toxic greens: a preliminary study on pesticide usage on golf courses in Northern Ireland and potential risks to golfers and the environment
}

\author{
C. A. Kearns \& L. Prior \\ School of Sociology, Social Policy and Social Work, \\ Queens University Belfast, Northern Ireland
}

\begin{abstract}
The pesticide hazards are well documented in their capacity to adversely affect public health and the environment. This paper presents information from a survey of pesticide usage practices on golf courses in Northern Ireland in 2008 and highlights the possible risks for golfers and for the environment from the use of the chemicals. The findings suggest that pesticides are being applied at high rates, on average $2.2 \mathrm{~kg} / \mathrm{ha}$. The most heavily treated areas of courses are greens and tees, mainly treated with fungicides. The principal reasons for use are to control fusarium, leatherjackets, earthworm casts and daisies. The principal pesticide types used overall are herbicides, with MCPA the most frequently used active ingredient. The most regularly used pesticides leach readily in soil and have been found in groundwater samples in Northern Ireland. The majority of compounds reported used are listed as being toxic to wildlife with some also being very toxic to the aquatic environment. Many of the pesticides used have the potential to adversely affect human health. Early removal of spraying notification found in the study may increase the risk of golfers coming into direct contact with pesticides.

Keywords: pesticide use, non-agricultural, amenity, golf courses, herbicide use, fungicide use, MCPA,2-4-D, Dicamba, pesticide risk.
\end{abstract}

\section{Introduction}

The use of pesticides on agricultural land and their associated hazards are well documented. However, pesticide usage is not solely confined to this area, with 
many pesticides being applied in non-agricultural situations. Statistics on nonagricultural pesticide use are limited in Northern Ireland.

Golf is a popular sport and golfing tourism is a major source of income to regional economies. Golf courses have a close interface with the environment occupying and managing large areas of the countryside. The environmental issues affecting golf courses involve; conserving biodiversity, they are oases for wildlife with the rough and out of play areas in particular being home to a rich diversity of plants, insects, animals and birds [1], landscape and cultural heritage, and sustainable resource management. Amenity turf on golf courses are intensively managed, driven by player demands to have aesthetically pleasing courses free of weeds and disease. There are concerns that pesticide usage is higher on golf courses than on agricultural grassland.

There is evidence from water quality monitoring studies of contamination of waters by non-agricultural herbicide use [2], raising ecological and human health concerns. The principal routes of entry for pesticides include surface runoff, spray drift and leaching into waterways. The routes by which bystanders are exposed to pesticide compounds may also be different from an agricultural setting. Bystander pesticide exposure can be as a result of being contaminated by spray drift or having direct contact with pesticide treated surfaces, having entered pesticide treated areas before the applied compound has sufficient time to disperse or degrade [3]. The likelihood of the latter may be increased in a golfing environment, where more people have potential access to, or are waiting to play on, areas that are treated.

It is not known what types of pesticide compounds are being used or the reason for their application on golf courses in Northern Ireland. The available number and range of pesticide products approved for use in both agricultural and non-agricultural settings has declined in recent years, giving an additional requirement to identify pesticide usage practices to ascertain environmental impact and also to inform policy.

This paper presents information from a survey of pesticide usage practices on golf courses in Northern Ireland in 2008, including; the types and quantities of pesticide active ingredients used, the reasons for the applications and the human and ecological risk potential of the pesticides.

\section{Methodology}

Using the Northern Ireland Statistics and Research Agency [4] listing of golf courses and the Golf Clubs of Ireland directory, a census of the entire population of golf courses in Northern Ireland was established identifying 100 courses. A letter of invitation was sent in November 2008 to the 100 golf courses, explaining the purpose of the study and inviting them to participate. Confidentiality was deemed as a priority ethical issue and all participants were informed both in the letter and again on the questionnaire that their responses would be confidential. Only clubs with a minimum of nine holes were considered as being a golf course. Eight clubs were excluded from the population as a result of not meeting this criterion. 
A questionnaire was structured around the design frame used for pesticide usage collection of data in the agriculture / horticulture sectors in Northern Ireland, [5]. Pesticide usage data collection on agriculture and horticulture crops has been operational in the UK from 1990 to comply with European requirements. The questionnaire was sent to 92 clubs requesting information relating to general information about the club and course and the pesticide usage practices. The pesticide data were based on the previous calendar year (2007) application. A pre-paid return envelope was included as an incentive to return. A Microsoft Access database was setup to manage the survey returns. A pilot study on six clubs was carried out prior to starting the main study, the results of which were included in the overall analysis. Of the 92 questionnaires sent, 44 were returned giving a response rate of $48 \%$.

Any part of the golf course may have; none, one, or more than one treatment applied to it. The 'basic area' (ha), is the actual area that was treated with a given pesticide, and the 'treated area' (spray hectares) is the area treated after multiple applications of pesticide. Data were analysed for both basic and treated areas. All pesticide products were converted into their active ingredient (s) for analysis. The rate of application of the products was recorded as litres or kilograms $(\mathrm{kg})$ of product per hectare and as both units are equivocal the results are given in $\mathrm{kg}$. Pesticides were grouped for the analysis into herbicides, fungicides, insecticides and growth regulators

Initial descriptive exploratory analysis was carried out and contingency tables were prepared and statistically tested to identify difference and/or relationships between groups. P-values of $<0.05$ using $95 \%$ confidence intervals (CI) were considered statistically significant. Data were analysed using Stata Vers. 10 statistical software.

\section{Results}

\subsection{Survey response}

Exactly 44 replies were received for a response rate of $48 \%$, representing almost half of all golf courses in Northern Ireland and providing a meaningful insight into pesticide use on golf courses in the region.

\subsection{Course profile}

The total land area coverage was 2,325 hectares. The rough area accounted for $65 \%$, fairways $30 \%$, greens $3 \%$ and the tees $2 \%$ of the total land area (Table 1 ). The distributions of course types in the study were Parkland (75\%), Links (9\%), Parkland/Link combination (9\%), Parkland/Heathland combination (5\%) and Heathland (2\%). The majority (77\%) of courses had 18 holes or more, giving a good representation of larger size courses. 
Table 1: The area (hectares) reported of golf courses in Northern Ireland, 2008.

\begin{tabular}{llllll}
\hline Course Type & Fairway & Green & Tee & Rough & Total \\
\hline Parkland & 524.47 & 36.64 & 30.81 & 1137.18 & 1729.10 \\
Links & 104.98 & 22.95 & 5.69 & 214.93 & 348.55 \\
Parkland/Links & 32.00 & 2.85 & 2.71 & 89.96 & 127.52 \\
Heathland & 14.88 & 0.80 & 0.50 & 32.38 & 48.56 \\
Parkland/Heathland & 19.44 & 1.60 & 1.60 & 48.21 & 70.85 \\
Total & 695.77 & 64.84 & 41.31 & 1522.66 & 2325.00 \\
\hline
\end{tabular}

\subsection{Age and construction of courses}

The majority $(55 \%)$ of courses were over 50 years old, with half of these courses being over 100 years old, $41 \%$ of courses were less than 50 years old, with $9 \%$ of these less than 10 years old, age was not known for the remaining $4 \%$. 39\% of golf courses were made up of a combination of natural and manmade areas, with $7 \%$ of all courses originally being farmland.

\subsection{Turfgrass species}

Turfgrass species were variable on greens and tees, between courses. The majority $(89 \%)$ of courses used mixes of grass species on greens, of these $87 \%$ included Agrostis spp. in combination with other species of grass. Mixed grass species including Agrostis spp. predominated also on tees. Eleven clubs used straight grass species on tees, with $55 \%$ of using Lolium perenne spp.

\subsection{Water features on courses}

Water features on courses were categorised as; contained, adjacent to course, running through all or part of the course or no water feature. Forty-one clubs had one or more water feature, with $48 \%$ of clubs having contained features, principally ponds and $40 \%$ having a river/stream moving through part or the entire course. An additional $6 \%$ of courses had either a river/stream or sea bordering the course. Greater than $60 \%$ of courses had a waterway either bordering or within one mile of the course or had a river/stream running through all or part of the course.

\subsection{Area and quantity of pesticide usage}

Of the 2,325ha of land area coverage reported in the survey, 1,106 ha (48\%) received a pesticide treatment, with almost 2.5 tonnes of pesticide applied. On average each hectare treated received $2.2 \mathrm{~kg}$ of pesticide. Almost all $(98 \%)$ greens on golf courses were treated, receiving on average $7.5 \mathrm{~kg} / \mathrm{ha}$, significantly more pesticide per hectare than any other part of the course. The proportion $(37 \%)$ of tees treated were lower than greens however the average pesticide amount applied $(5.8 \mathrm{~kg} / \mathrm{ha})$ was also high. An estimated $81 \%$ of all fairways on 
courses received a pesticide treatment with average dosage of $2.1 \mathrm{~kg} / \mathrm{ha}$ (Table 2). Twenty (45\%) clubs applied a treatment to the rough areas of courses, with $31 \%$ of the entire rough area receiving a pesticide treatment. The principal active ingredients used on the rough areas of courses were MCPA, Mecoporop-p and Dicamba.

Table 2: $\quad$ Areas of course treated and quantity of active ingredients (a.i.) applied.

\begin{tabular}{lcccccc}
\hline $\begin{array}{l}\text { Course } \\
\text { area }\end{array}$ & $\begin{array}{c}\text { Actual } \\
\text { area } \\
\text { (ha) }\end{array}$ & $\begin{array}{c}\text { Basic } \\
\text { area } \\
\text { treated } \\
\text { (ha) }\end{array}$ & $\begin{array}{c}\text { Treated } \\
\text { area } \\
\text { (spha) }\end{array}$ & $\begin{array}{c}\text { Quantity } \\
\text { of a.i. } \\
\text { (kg) }\end{array}$ & $\begin{array}{c}\text { Quantity } \\
\text { a.i./basic } \\
\text { area } \\
\text { (kg/ha) }\end{array}$ & $\begin{array}{c}\text { Quantity } \\
\text { a.i./ } \\
\text { treated } \\
\text { area } \\
\text { (kg/spha) }\end{array}$ \\
\hline Fairway & 695.77 & 560.28 & 1833.09 & 1180.86 & 2.1 & 0.6 \\
Green & 64.84 & 63.5 & 237.1 & 479.2 & 7.5 & 2 \\
Tee & 41.31 & 15.39 & 69.01 & 88.88 & 5.8 & 1.3 \\
Rough & 1522.66 & 467.2 & 1243.13 & 750.31 & 1.6 & 0.6 \\
Total & 2324.58 & 1106.37 & 3382.33 & 2499.25 & 2.2 & 0.7 \\
\hline
\end{tabular}

\subsection{Types of pesticide}

Twenty-seven pesticide active ingredients were applied to golf courses, of these; $52 \%$ were herbicides, $34 \%$ fungicides, $7 \%$ insecticides and $7 \%$ growth regulators. The top eight active ingredients are shown in Table 3.

Table 3: $\quad$ Top 8 Active ingredients used on golf courses, prioritised by spha.

\begin{tabular}{lccc}
\hline Active Ingredient & Quantity (kg) & Treated area (spha) & kg/spha \\
\hline MCPA & 786.12 & 777.63 & 1.01 \\
Mecoprop-P & 529.70 & 646.39 & 0.82 \\
Dicamba & 57.30 & 523.80 & 0.11 \\
2,4-D & 376.55 & 353.85 & 1.06 \\
Diflufenican & 14.22 & 315.28 & 0.05 \\
Clopyralid & 28.13 & 314.28 & 0.09 \\
Chlorpyrifos & 77.40 & 136.68 & 0.57 \\
Iprodione & 130.71 & 62.19 & 2.10 \\
\hline
\end{tabular}

Over all herbicides were the most frequently used pesticide group, applied to $90 \%$ of the pesticide-treated area. The principal reason for application was to control daisies. The majority (57\%) of herbicide applications were on to fairways with an additional $40 \%$ applied to the rough areas of the course. The herbicide active ingredient MCPA was the most widely used pesticide overall with an estimated $786 \mathrm{~kg}$ applied during the study period. The herbicide active ingredients Mecopprop-P, 2,4-D, and Dicamba were also widely used with Dicamba being used at lower rates than the others. 
Fungicides were applied to $5 \%$ of the total pesticide-treated area, accounting for $21 \%$ of the quantity of all pesticides applied. The average amount of fungicide applications differed between course types $(\mathrm{P}<0.043)$ with applications to greens on links courses higher than other course types. Chlorothalonil, Iprodione and Carbendazim were the principal fungicide active ingredients used with Chlorothalonil applied at high rates. The majority $(57 \%)$ of fungicides were applied to control fusarium (Microdochium patch) disease. The principal reason for application of fungicides on tees was to control earthworm casts.

Insecticides were applied to $4 \%$ of the pesticide-treated area and accounted for only $3 \%$ of all pesticides used on courses. The majority (57\%) of insecticides were applied to greens. There were only two insecticide active ingredients reported used, Chlorpyrifos (99\%) and Imidacloprid. Leatherjackets (Tipula spp.) were the principal reason for insecticide applications, (Table4).

Table 4: The quantity and area treated by pesticide group by area on golf course.

\begin{tabular}{lcccccccccc}
\hline & \multicolumn{2}{c}{ Fungicide } & \multicolumn{2}{c}{ Herbicide } & \multicolumn{2}{c}{ Insecticide } & \multicolumn{2}{c}{ G. regulator } & \multicolumn{2}{c}{ Total } \\
& $\mathrm{spha}$ & $\mathrm{kg}$ & $\mathrm{spha}$ & $\mathrm{Kg}$ & $\mathrm{Spha}$ & $\mathrm{kg}$ & $\mathrm{spha}$ & $\mathrm{kg}$ & $\mathrm{spha}$ & $\mathrm{kg}$ \\
\hline Fairway & 19.8 & 53.1 & 1757.7 & 1068.9 & 48.4 & 28.4 & 7.3 & 30.5 & 1833.1 & 1180.9 \\
Green & 136.3 & 423.2 & 13.1 & 7.9 & 78.7 & 43.1 & 9.0 & 5.0 & 237.1 & 479.2 \\
Tee & 15.6 & 58.5 & 38.7 & 20.8 & 9.9 & 5.9 & 4.8 & 3.6 & 69.0 & 88.9 \\
Rough & $*$ & $*$ & 1243.1 & 750.3 & $*$ & $*$ & $*$ & $*$ & 1243.1 & 750.3 \\
Total & 171.7 & 534.8 & 3052.6 & 1847.9 & 136.9 & 77.4 & 21.1 & 39.1 & 3382.3 & 2499.3 \\
\hline
\end{tabular}

\subsection{Comparison with agriculture grassland pesticide use}

The overall average pesticide rate on golf courses of $2.5 \mathrm{~kg} / \mathrm{ha}$ was higher than rates on agricultural grassland reported for 2009 in Northern Ireland, with averages between 1.2 and $1.7 \mathrm{~kg} / \mathrm{ha}$ [6]. However, average rates of pesticides on the rough grassland areas were similar in both the amenity and agriculture settings. Pesticide usage rates on fairways were also higher than the overall average agriculture rate. There was no recorded fungicide used on agriculture grassland in 2009. A low amount of insecticide was applied to enclosed agriculture grassland at a rate of $0.01 \mathrm{~kg} / \mathrm{spha}$ [6]. In comparison the study reported a higher average insecticide rate of $0.6 \mathrm{~kg} / \mathrm{spha}$ applied to golf courses (Table 5).

\subsection{Notification of spraying}

Forty clubs provided information on spray notification practices, of these $95 \%$ notified golfers prior to spraying and $84 \%$ of them put a sign on the first tee of the course. Clubs were asked the time period prior to spraying that signs were issued; $81 \%$ notified golfers on the day of spraying. The period after spraying 
when notification was removed varied with $21 \%$ of clubs removing notifications either immediately after spraying or within four hours of completion.

Table 5: Average rates of pesticides on golf courses and agriculture grassland.

\begin{tabular}{lcc}
\hline & $\begin{array}{c}\text { Kg/ha (basic area } \\
\text { treated) }\end{array}$ & $\begin{array}{c}\text { Kg/spha (all } \\
\text { treated) }\end{array}$ \\
\hline NI Golf courses overall & 2.5 & 0.7 \\
Golf course Fairways & 2.1 & 0.6 \\
Golf course Greens & 7.5 & 2.0 \\
Golf course Tees & 5.8 & 1.3 \\
Golf course Rough & 1.6 & 0.6 \\
*Agriculture Rough grassland & 1.7 & 1.7 \\
*Agriculture $\quad$ managed & 1.2 & 0.9 \\
(enclosed) grassland & & \\
\hline
\end{tabular}

*Withers et al. [6].

Table 6: Indicators of risk of principal pesticides used on golf courses in NI.

\begin{tabular}{|c|c|c|c|c|c|c|c|}
\hline & Health & $\begin{array}{l}\text { Toxic } \\
\text { aquatic }\end{array}$ & $\begin{array}{l}\text { Toxic } \\
\text { birds/bees }\end{array}$ & $\begin{array}{l}\text { Persist- } \\
\text { ence }\end{array}$ & Leach & $\begin{array}{l}\text { PAN/ } \\
\text { FOE list } \\
{[15,16]}\end{array}$ & $\begin{array}{l}\text { In } \\
\text { UK/NI } \\
\text { water }\end{array}$ \\
\hline $\mathrm{MCPA}$ & Yes & Low- & Med. & Low & High & Yes & Yes \\
\hline Mecoprop-P & Yes & Low & Low & Med. & Low & Yes & Yes \\
\hline $2,4, \mathrm{D}$ & Yes & No & Med-high & Low & Med. & No & Yes \\
\hline Dicamba & Slight & Low & Low & Med. & High & Yes & Yes \\
\hline Chlorothalonil & Yes & High & No & Med. & Low & Yes & No \\
\hline Iprodione & Yes & Med. & Low & Low & Low & Yes & No \\
\hline Carbendazim & Yes & High & Low & $\begin{array}{l}\text { Med- } \\
\text { high }\end{array}$ & Low & Yes & Yes \\
\hline Chlorpyrifos & Yes & High & High & $\begin{array}{l}\text { Med- } \\
\text { high }\end{array}$ & Low & Yes & No \\
\hline
\end{tabular}

\subsection{Ecological and environmental risk indicators}

An estimate of risk indicators ranked high, medium and low for the principal pesticides used on the golf courses in Northern Ireland are shown in Table 6. Whether or not the chemicals were found in UK or NI surface or groundwater in the past few years is also included as is whether they have been listed by either the Pesticide Action Network (PAN) or the Friends Of the Earth (FOE) 'bad actor' or 'filthy four' lists, respectively. The pesticides included in these lists have at least one of the following; possible or known, carcinogen, reproductive/developmental toxicant, neurotoxin, groundwater contaminant or have high acute toxicity. 


\section{Discussion}

This study provides a snapshot of pesticide usage on golf courses in Northern Ireland during the 2007 growing season. The findings in the paper suggest that high rates of pesticides are being used on golf courses with the overall average rate of pesticides applied to courses higher than both managed and non-intensive agriculture grassland. The areas of the course that were most heavily treated were the highly managed greens and tees receiving high amounts of fungicides and insecticides. Pest and disease problems found on courses in Northern Ireland are similar to elsewhere in the United Kingdom [7]. The condition of tees and greens are important to golfers with the latter being the principal factor in judging a golf course [8]. They are also the areas of the course where golfers are most likely to come into direct contact with the turf while placing their ball.

Almost two-thirds of the area reported in the study consisted of rough (nonplaying areas). These are mainly areas of natural habitat. The age of a golf course is an important factor in determining its value for wildlife, with conservation value likely to be greater in older sites [9]. The largest proportion of courses in the study were over 50 years old with one quarter of sites over 100 years old suggesting the likelihood of large areas of well established natural habitat, with a richer biodiversity, supporting most likely a variety of wildlife and flora. Almost one-third of the rough area received at least one pesticide application with an average pesticide rate of $1.6 \mathrm{~kg} / \mathrm{ha}$. All pesticides applied on these areas had toxic properties towards wildlife ranging from low to high toxicity.

The majority of clubs had a water feature on the course, with almost half reporting having a river or stream either moving through or adjacent to the course. A large proportion (48\%) of courses reported having at least one pond on the course. Residue of pesticides entering ponds are thought to have the potential to persist for longer with recovery periods of impacted populations also taken longer than for flowing water bodies [10]. The potential for surface run-off and spray drift from pesticides entering water systems is also much greater the closer the waterways are to the area sprayed. Water features were located throughout the courses. To accurately estimate this however, a monitoring study would be required. The potential leaching capacity of the principal active ingredients reported in the study ranged from low to high with five of the nine principally used active ingredients in the study also found in ground or surface water in the United Kingdom in the last few years. MCPA, the most widely used pesticide in the survey was found in groundwater in Northern Ireland in 2011, breaching the drinking water safety regulatory standard [11]. Furthermore, in a recent report by the British Geological Society [12], following a hazard assessment based on persistence and leaching indices, the following chemicals, all of which were reported used on golf courses in the study, were listed as having the greatest potential of leaching into water: MCPA, 2,4-D,Clopyralid, Dicamba and Metsulfuron-methyl. Further research should consider evaluating the likelihood of these compounds being leached into waterways from amenity areas such as golf courses. 
In amenity turf, recreational exposure is thought to be higher than occupational exposure of workers [13]. Golfers, often playing shortly after pesticide applications may be exposed directly to treated turf or from pesticide vapours or mist. Unlike agriculture where guidance is given when livestock can enter treated area, there is no clear guidance on time period for re-entry after spraying in amenity areas. One-fifth of clubs in the study removed notification of spraying either immediately or within four hours of applying pesticides, with a small minority of clubs not notifying golfers at all of spraying, suggesting a heightened risk of golfers coming into direct contact with pesticides.

While the majority of chemicals used in the survey all had some level of toxicity to humans the levels were principally low. Quantification of risk of chemicals to humans is complex. However, even low levels of exposure are thought to have the potential to suppress the immune system in humans [14]. Many of the pesticides used in the amenity sector were firstly registered as products for agricultural use and subsequently passed for amenity usage. Is there a requirement for legislators to have additional adjustment factors for estimating risk on these products when used in the amenity sector?

There is a future need to routinely collect pesticide usage information on golf courses to provide accurate data on types and quantities of pesticide used, to allow regulators to: estimate exposure levels in this environment, identify health or environmental risks and also to identify areas for less toxic alternatives or indeed improvements in management practices to reduce chemical input.

\section{References}

[1] Duff, K. and Symes, N., Birds and Golf Courses: A Guide to Habitat Management- RSPB and the R7A (UK), 2009

[2] Kristoffersen, P., Rask, A.M., Grundy, A.C., Franzen, I., Kempenaar, C., Raisio, J., Schroeder, H., Spijker, J., Verschwele, A. and Zarina, L., "A review of pesticide policies and regulations for urban amenity areas in seven European countries", Weed Research, vol. 48, pp. 201-214, 2007

[3] Stephenson, G.R. and Ritcey, G.M., "Dislodgeable foliar residues of pesticides in agricultural, landscape and greenhouse environments." In Echobichon, D.J. (ed.) Occupational Hazards of Pesticide Exposure. London: Taylor \& Francis, pp. 51-80, 1998.

[4] NISRA. 2005, Neighbourhood Statistics for Northern Ireland. Available: www.ninis.nisra.gov.uk/mapxtreme/viewdata/Locatins/Golf_Courses_Oct2 005.xls [2008, June].

[5] Thomas, M.R., "Pesticide Usage Monitoring in the United Kingdom", Annals of Occupational Hygiene, vol. 45, no. 1001, pp. 87-93, 2000.

[6] Withers, J.A., Jess, S., Matthews, D., and Kelly, T., Pesticide Usage Survey Report 238: Northern Ireland Grassland and Fodder Crops, 2009 Available: www.afbini.gov.uk/pusg-survey-report238

[7] Mann R.L. and Newell, A.J., "A survey to determine the incidence and severity of pests and diseases on golf course putting greens in England, 
Ireland, Scotland and Wales" International Turfgrass Society; Research Journal Vol.10, pp. 224-229, 2005.

[8] Anon. 2012, "Study of golf player perceptions, satisfaction and desires for golf course management" Available: http://www.greencast.co.uk/uk/news/ product-news/golf-survey.aspx

[9] Gange, A.C. and Case, S.J., "Incidence of microdochium patch disease in golf putting greens and a relationship with arbuscular mycorrhizal fungi", Grass and Forage Science, vol. 58, pp. 58-62, 2003.

[10] Brown, C.D., Turner, N., Hollis, J., Bellamy, P., Biggs, J., Williams, P., Arnold, D., Pepper, T. and Maund, S., "Morphological and physic-chemical properties of British aquatic habitats potentially exposed to pesticides", Agriculture, Ecosystems and Environment, vol. 113, pp. 307-319, 2006.

[11] NIEA (2012) Drinking water quality in Northern Ireland, 2011. Available: www.doeni.gov.uk/niea/water-home/dinkingwater.htm

[12] Stuart, M.E., Manamsa, K., Talbot, J.C. and Crane, E.J., Emerging contaminants in groundwater. British Geological Survey Open Report, OR/11/013. 123 pp. 2011.

[13] Godson, T.D., "Regulatory Concerns with Pesticide Use in Turf", Pesticide Science, vol. 46, pp. 371-378, 1996.

[14] WRI, 1996. Pesticides and the immune system: the Public Health Risks Repetto R. \& Baliga S.S., World Resources Institute, Baltimore.

[15] Pesticide Action Network; PAN Pesticide database- Chemicals. Available: http://www.pesticideinfo.org/Detail_Chemical.jsp?Rec_Id=PC34588

[16] Friends of the Earth, The 'Filthy Four' pesticides, briefing, May 2000, In “Carbendazim", Pesticides News No. 57, September 2002, pp. 20-21 Available: http://www.pan-uk.org/pestnews/Actives/Carbenda.htm 